\title{
PROPOSTA LÚDICA PARA ENSINO DO CONTEÚDO DAS DOENÇAS INFECCIOSAS E PARASITÁRIAS QUE AFETAM O HOMEM
}

\author{
Marcos Vinícius Domiciano Santos ${ }^{1}$ \\ Liliam Martins Marcolino ${ }^{2}$ \\ Flavia Villaça Morais ${ }^{3}$
}

\begin{abstract}
Resumo: Os materiais lúdicos, incluindo jogos, são ferramentas importantes para construção do processo de ensino-aprendizagem, pois essa interação cativa o aluno, criando assim laços cognitivos e afetivos. $O$ aprender-brincando é um método valioso e muito estudado, pois de uma maneira mais atraente o aluno tem capacidade de unir o brincar, com o fixar dos conceitos "científicos" abordados. Como os Parâmetros Curriculares Nacionais mencionam, é de extrema importância que a escola passe conceitos relacionados à saúde, pois o aluno tem a capacidade de ser o agente disseminador desse conhecimento para sua comunidade. Nesse contexto, o prezado trabalho tem por finalidade criar um material lúdico (jogo), que auxilia o professor no conteúdo, sobre as doenças infecciosas e parasitárias que afetam o homem. Assim o jogo de tabuleiro foi criado, com base em jogos conhecidos e de fácil manipulação, considerando a literatura sobre jogos didáticos e material específico das doenças. Podemos então concluir que o tema das doenças infecciosas e parasitárias, é de grande relevância para o aluno, e pode ser aprendido através da brincadeira entre colegas e professor.
\end{abstract}

Palavras-chave: Ensino-aprendizagem; Aprender-brincando; Material lúdico; Saúde.

\footnotetext{
${ }^{1}$ Ciências Biológicas/Universidade do Vale do Paraíba, Brasil. E-mail: mvds.domiciano@gmail.com.

2 Ciências Biológicas/Universidade do Vale do Paraíba, Brasil. E-mail: liliamm@pitagoras.com.br.

${ }^{3}$ Ciências Biológicas/Universidade do Vale do Paraíba, Brasil. E-mail: flavia@univap.br.
} 